\title{
Improved Approach to Determine the Material Parameters for a Combined Hardening Model
}

\author{
Benjamin Seisenbacher, Gerhard Winter, Florian Grün \\ Department Product Engineering, Chair of Mechanical Engineering, Leoben, Austria \\ Email: amb@unileoben.ac.at
}

How to cite this paper: Seisenbacher, B. Winter, G. and Grün, F. (2018) Improved Approach to Determine the Material Parameters for a Combined Hardening Model. Materials Sciences and Applications, 9, 357-367.

https://doi.org/10.4236/msa.2018.94024

Received: February 15, 2018

Accepted: April 10, 2018

Published: April 16, 2018

Copyright $\odot 2018$ by authors and Scientific Research Publishing Inc. This work is licensed under the Creative Commons Attribution-NonCommercial International License (CC BY-NC 4.0). http://creativecommons.org/licenses/by-nc/4.0/

\begin{abstract}
For the simulation of isothermal mechanically loaded components, it is indispensable to have a material model, which describes the material behavior very accurately. In this case, a combined hardening model was chosen in order to reflect the prevalent deformation behavior. The combined hardening model enables simulation independent of the number of load cycles and the chosen strain amplitude. The main point is the declaration of the parameters from the chosen material model. This work deals with the estimation of the parameters. For validation and as input data of the here defined approach low cycle fatigue (LCF) tests were performed on cast aluminum and at $250^{\circ} \mathrm{C}$. The comparison of the test results and the simulations indicated that $\sigma_{\max }$ from the simulated hysteresis lies inside a range of $\pm 5 \%$ referred to the test results.
\end{abstract}

\section{Keywords}

Low Cycle Fatigue, Simulation, Combined Hardening Model, Parameter Estimation, Plasticity

\section{Introduction}

The result of the pursuit for more efficient and lighter components is that the loading conditions and the requirements on the materials are increasing. If the loading conditions exceed the elastic material behavior plastic strain occurs [1]. This means that material behavior changes from an elastic into a non-proportional inelastic behavior. Further factors, which influence the material behavior, are the temperature and the rate how an external load is applied. If components are subjected to such loading conditions, it is necessary to understand the material's response. With the results from isothermal LCF tests, it is possible to examine the inelastic material behavior. For designing and simulation the material behavior has to be pictured out by mathematically models. One popular model, 
which covers such effects, is the Ramberg-Osgood-model [2]. The model deals with the description of elastic and inelastic areas from stress strain curves. Two linear kinematic models, which take the plastic range of the material behavior into account, are the Prager [3] and Ziegler [4] hardening rules. Based on the linear kinematic model from Prager, Amstrong and Frederic [5] developed a nonlinear kinematic model. The time independent behavior from the yield stress is considered in the isotropic part of the Chaboche-model [6], which also includes the nonlinear kinematic model from Amstrong and Frederic.

In this paper, the material behavior of cast aluminum is declared by using a combined hardening model. A modified Chaboche model represents the combined hardening model. The Chaboche model is changed by replacing the Prager hardening rule through the Ziegler hardening rule. The challenge is the estimation of the parameters of the combined hardening model. Therefore, a Matlab ${ }^{\circledR}$ routine was established, which deals with the determination of the parameters from the combined hardening model. As input data for the combined hardening parameter (CHP) routine the hysteresis of the conducted LCF tests were taken. At the end, finite element simulation with Zebulon ${ }^{\circledR}$ was carried out. The present work will focus on the estimation of the parameters based on the LCF test results.

\section{Material Model}

A combined hardening model has been chosen for the reproduction of the material behavior. Based on the Chaboche model the combined hardening law include a kinematic and isotropic hardening law. The main equation that expresses the used model is:

$$
F=f(\sigma-\alpha)-R-R_{0}
$$

where $F<0$ represents the elastic part and if $F=0$ plastic flow takes place. The evolution of the yield surface is taken into account in the back stress $\alpha$ and in the drag stress $R$ [7] [8]. Thereby the back stress $\alpha$ represents the translation and the drag stress $R$ the cyclic hardening behavior. The yield surface obeys the Von Mises criterion:

$$
f(\sigma-\alpha)=\left[\frac{3}{2} *(\sigma-\alpha):(\sigma-\alpha)\right]^{\frac{1}{2}}
$$

The back stress $R$ represent the isotropic part, which deals with the increase or decrease of the yield surface, depending on the accumulated plastic strain. $R_{0}$ conforms to the initial yield stress by zero accumulated plastic strain $\dot{p}$. The back stress $\mathrm{R}$ is described by following equation:

$$
\dot{R}=b^{*}(Q-R) * \dot{p}
$$

For the consideration of the translation of the yield stress the non-linear kintmatic hardening law of Frederick-Armstrong was used. Thereby the Prager hardening rule is replaced through the Ziegler hardening rule. In this case the 
kinematic hardening is given through following equation:

$$
\dot{\alpha}=C \frac{1}{\sigma_{0}} *(\sigma-\alpha) * \dot{\varepsilon}_{p}-\gamma^{*} \alpha * \dot{\varepsilon}_{p}
$$

As shown in [9] [10] and under consideration of [11] the explicit integration of the kinematic hardening Equation (4) over an uniaxial strain cycle with the first data pair $\left(0, \alpha_{1}\right)$ gives following equation:

$$
\alpha=\frac{C}{\gamma} *\left(1-\mathrm{e}^{\left(-\gamma * \varepsilon_{p}\right)}\right)+\alpha_{1} * \mathrm{e}^{\left(-\gamma * \varepsilon_{p}\right)}
$$

\section{Experimental Procedure}

As input data for the CHP routine LCF test results were used. The tests were carried out on a servo-hydraulic testing machine type 8802 produced by the company Instron ${ }^{\circledR} \mathrm{GmbH}$. An Instron ${ }^{\circledR} \mathrm{GmbH}$ controller type Fast Track 8800 handled the data collection and the controlling. All tests were made strain rate controlled and under a strain-ratio of $R_{\varepsilon}=-1$. The tested material was cast aluminum and Figure 1 shows the test specimen geometry.

Tests were carried out at $250^{\circ} \mathrm{C}$, different heat treatments and by different strain amplitudes, as Table 1 shows. All LCF investigations were performed in consideration of the recommended standards for LCF testing, according to DIN EN 3988 and ISO 12106.

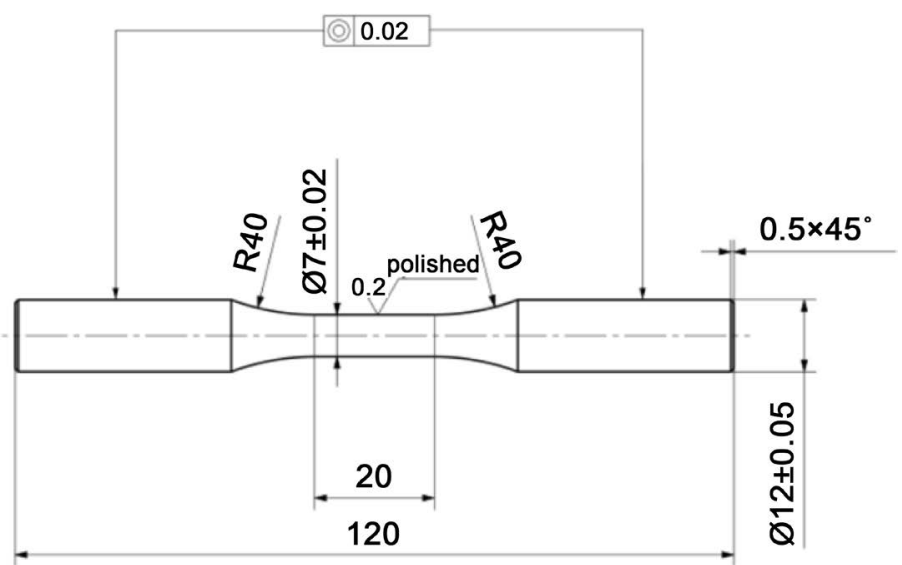

Figure 1. Drawing of the test specimen, which was used for LCF tests.

Table 1. Executed tests.

\begin{tabular}{cccc}
\hline test & head treatment & test temperature & Strain amplitude \\
\hline LCF_1_T6 & $\mathrm{T} 6$ & $250^{\circ} \mathrm{C}$ & $0.3 \%$ \\
LCF_2_T6 & $\mathrm{T} 6$ & $250^{\circ} \mathrm{C}$ & $0.3 \%$ \\
LCF_3_T6 & $\mathrm{T} 6$ & $250^{\circ} \mathrm{C}$ & $0.3 \%$ \\
LCF_4_T6 & as cast & $250^{\circ} \mathrm{C}$ & $0.2 \%$ \\
LCF_5_T6 & as cast & $250^{\circ} \mathrm{C}$ & $0.3 \%$ \\
LCF_6_T6 & as cast & $250^{\circ} \mathrm{C}$ & $0.4 \%$ \\
\hline
\end{tabular}




\section{Parameter Definition}

If a material model was selected a major rule plays the determination of the parameters, in regard to be able to generate exact simulation. To deal with the estimation of the material parameters the CHP routine was developed. The routine can be divided into two parts. The first part handles the estimation of the parameters and the simulation from the cycle on which the kinematic parameters were declared. If this simulation match with the test results, the second part of the CHP routine can be follow. The second part looks whether the data set from the first part can also describe the hysteresis at any other cycle. In the case that the simulation don't match, the isotropic parameters were adjusted. Every CHP routine controlled simulation were realized with Zebulon ${ }^{\circledR}$. The creation of the input file and the editing of the simulation results were done by the CHP routine. It has to be pointed out that for the use of the CHP routine following boundary conditions has to be complied from the test data:

- The shape from the hysteresis has to be symmetric.

- The stress curve in the nonlinear range has to be identical at each cycle.

The most aluminum and steel alloys show such a behavior [12] [13]. For materials (e.g.: grey cast iron), which not conform to the first determined material behavior, other material models has to be chosen, as demonstrated in [14] [15].

Figure 2 present an overview of the steps which are executed in the first part of the CHP routine. At first, the input data must be loaded and the boundary condition for the second step has to be specified. The analysis of the input data takes place in the second step. Thereby the significant values, such as $\sigma_{\max }, \mathrm{E}, \mathrm{R}$, of each hysteresis were declared. Based on these values, in the third step the isotropic parameters were estimated. The fourth step deals with the determination of the kinematic hardening parameters. At the beginning of step four the cycle, at which the kinematic hardening parameters were declared, has to be defined. This cycle serves also as initial cycle for the simulation step. The fifth step is the simulation step. Therefore, the parameters from the third and fourth step had been combined to one material model and saved in the input file. After simulation, the output file is read by the CHP routine and compared with the test data from the simulation cycle.

The most critical point in the estimation of the material parameters are the definition of the $\mathrm{R}$ values, which is done in the second step of CHP routine. For the definition of $\mathrm{R}$ the young modulus of each cycle has to be declared. Zhou et al. [16] and Fournier et al. [8] use a linear regression on the points located between two offset parameters. The two offset parameters were declared at the beginning of the second step. In this case, the offset parameters are determined by $\sigma_{\text {offsetmin }}$ and $\sigma_{\text {offsetmax }}$ as shown in Figure 3(a). After this, the regression line will be displaced with the offset parameter $\varepsilon_{\text {offset }}$ and cut with the hysteresis arm. This is plotted in Figure 3(a). The point of intersection represents the crossover from elastic to the plastic material behavior. Furthermore also the $\mathrm{R}$ value will be specified by this point. 


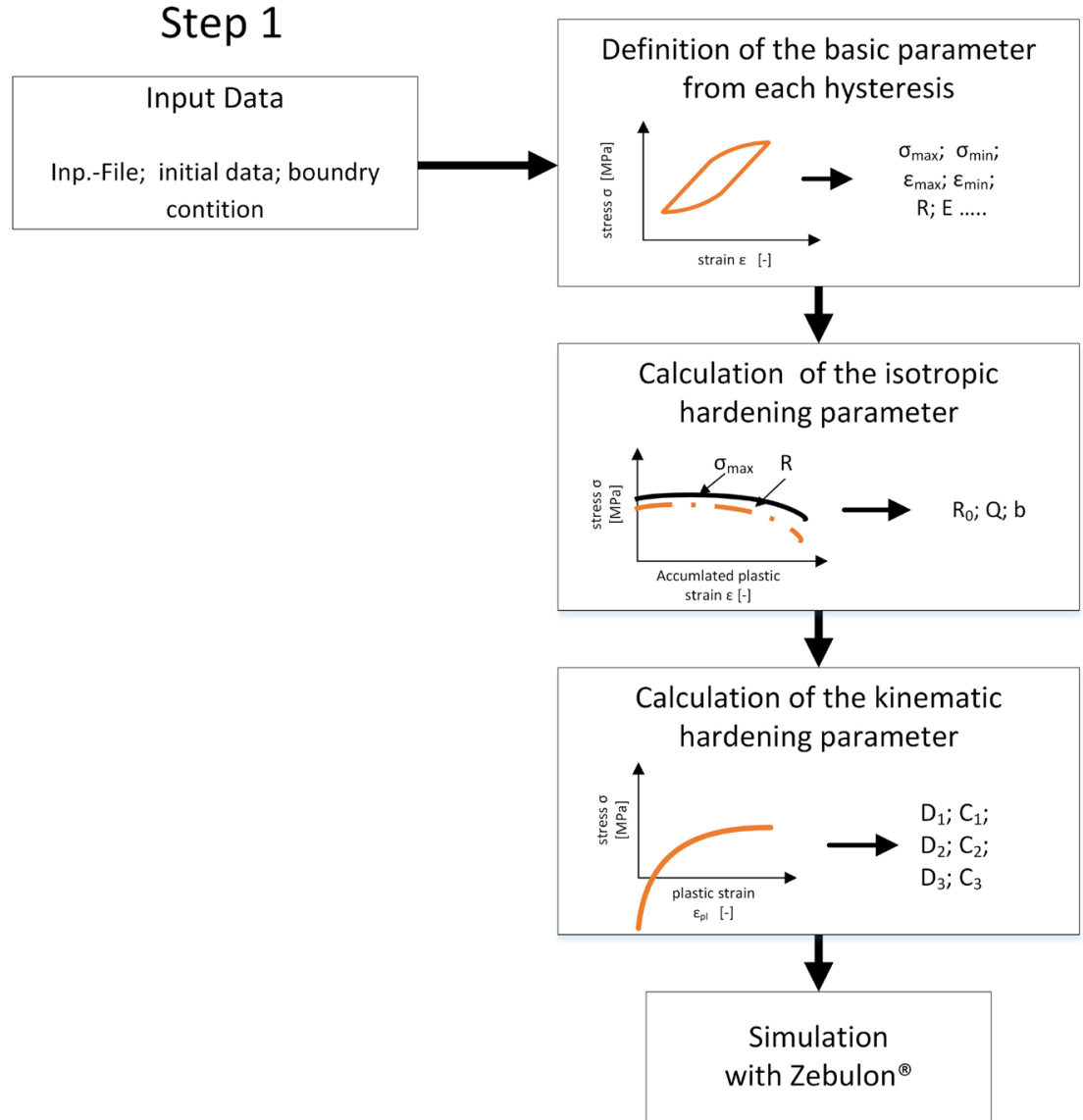

Step 2

Step 3

Step 4

Figure 2. Flow chat from the first part of the CHP routine.

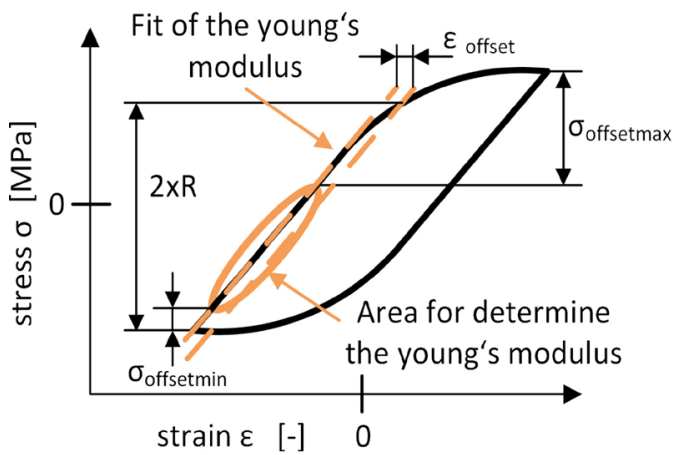

(a)

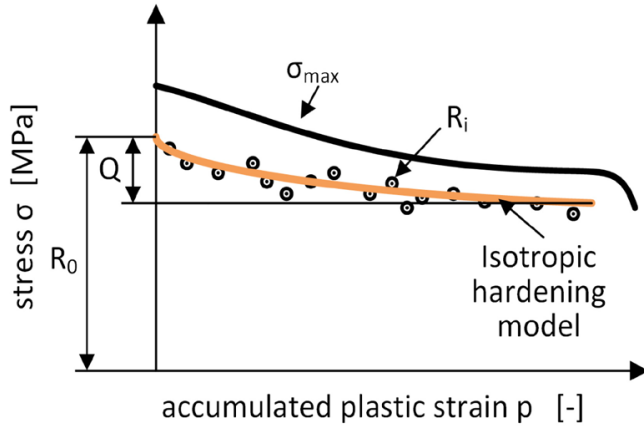

(b)

Figure 3. Preparing data for the isotropic parameter fit. (a) Determination of Young's Modul and R values, (b) isotropic hardening.

If the $\mathrm{R}$ values are estimated for each cycle, in the next step the isotropic hardening parameters $R_{0}, \mathrm{Q}$ and $\mathrm{b}$ were declared. $R_{0}$ represents the initial yield stress and the other parameters are fitted with the linear least-squares fitting method. Figure 3(b) shows the connection of the isotropic hardening law. If there are more than one input data set, for each data set the isotropic parameters were calculated. The currently used isotropic parameter set is declared by the mean value of the individual parameter set. 
In the fourth step of the first part from the CHP routine, the kinematic hardening parameters were defined. The input data should be extract from a cycle, which shows a big hysteresis, $\mathrm{N}_{\mathrm{kin}}$ defines this cycle. From the selected hysteresis, the data of the nonlinear range serve as input data for the calculation of the kinematic hardening parameters.

At the end of the first part from the CHP routine a simulation with the currently estimated parameters is done. The simulation result of the cycle $\mathrm{N}_{\text {kin }}$ is compared with the test results. If the simulation match with the test hysteresis the second part of the CHP routine can be done.

The second part looks whether the data set from the first part can also describe the hysteresis at any other cycle. How the second part of the CHP routine works can be seen in Figure 4. In the first step, of the second part, the input file and the associated simulation were handled. At the beginning of the first step the cycle numbers of the hysteresis, which will be simulated, has to be specified. The second part shows the results of the simulation and includes the optimization part. If the result of the first simulation doesn't match, an optimization of the isotropic hardening parameters takes place. After the optimization, it goes back to the first step, where in place of the parameters from the first part the optimized parameters were taken into account. Otherwise, the used parameters are the parameters, which are able to reflect the material behavior.

If an optimization is necessary, the $\mathrm{R}$ values have to be adapted. Therefore, the deviation of the simulation and the test results has to be defined. Based on the difference of the $\sigma_{\max }$ from the simulation hysteresis and the test hysteresis the R values were modified. This modified $\mathrm{R}$ values were taken as input data for the fit of the new isotropic hardening parameters.

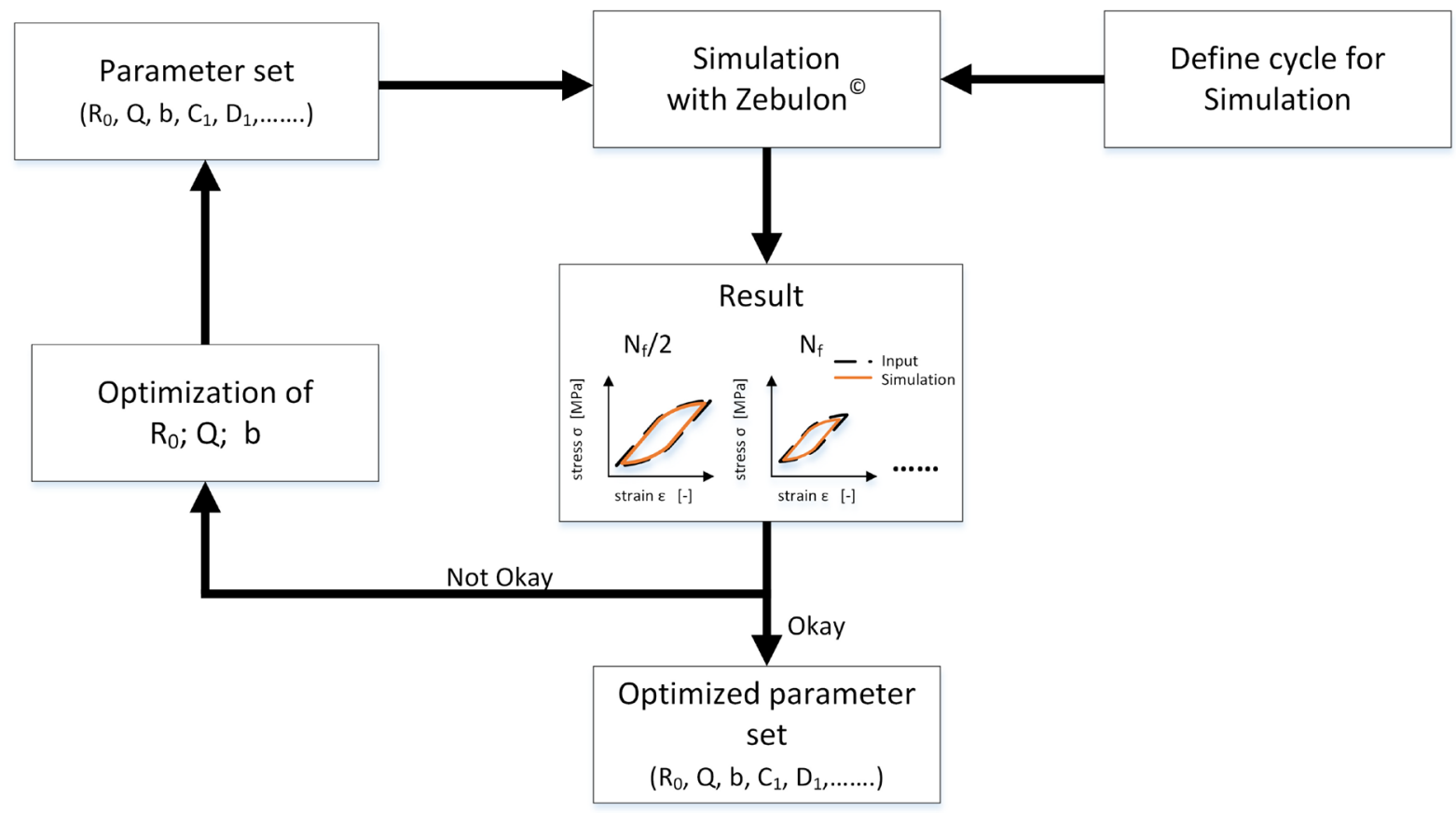

Figure 4. Flow chat from the second part of the CHP routin. 


\section{Results and Discussion}

To extract the combined hardening parameters, from the executed LCF tests, the $\mathrm{CHP}$ routine was used. All analysis were fitted at the lower hysteresis arm and the boundary conditions were chosen as following:

- $\sigma_{\text {offsetmax }}=0.5^{\star} \sigma_{\max }$

- $\sigma_{\text {offsetmin }}=0.05^{\star} \sigma_{\text {min }}$

- $\varepsilon_{\text {offset }}=0.00001$

In Figure 5 the tested hysteresis, of the $2000^{\text {th }}$ cycle with a heat treatment of T6, are printed out. The reference value is the mean value $\sigma_{\text {mean }}$ of the $\sigma_{\text {testmax }}$ of the currently investigated hysteresis. Figure 5 shows that $\sigma_{\text {testmax }}$ lies inside a scatter of $\pm 5 \%$ regarding to $\sigma_{\text {mean }}$. On basis of these test data the combined hardening parameter for the $2000^{\text {th }}$ cycle were generated with the CHP routine. The simulated hysteresis, based on the determined parameter, is shown in Figure 5. The $\sigma_{\max }$ of the simulated hysteresis lies within the range of $\pm 5 \%$ regarding to $\sigma_{\text {mean }}$.

In order to check out if the parameters from above can describe the material behavior also by another cycle, the second part of the OCP routine is used. In Table 2 the $\sigma_{\max }$ of the selected test cycles are given.

The first simulation displayed that for some cycle the variance between $\sigma_{\max }$ and $\sigma_{\text {mean }}$ is greater than $5 \%$. Therefore, an optimization of the isotropic hardening parameters took place. The results of the simulation, with the optimized parameter, shows that the $\sigma_{\max }$ for each cycle are inside the range of $\pm 5 \%$. The

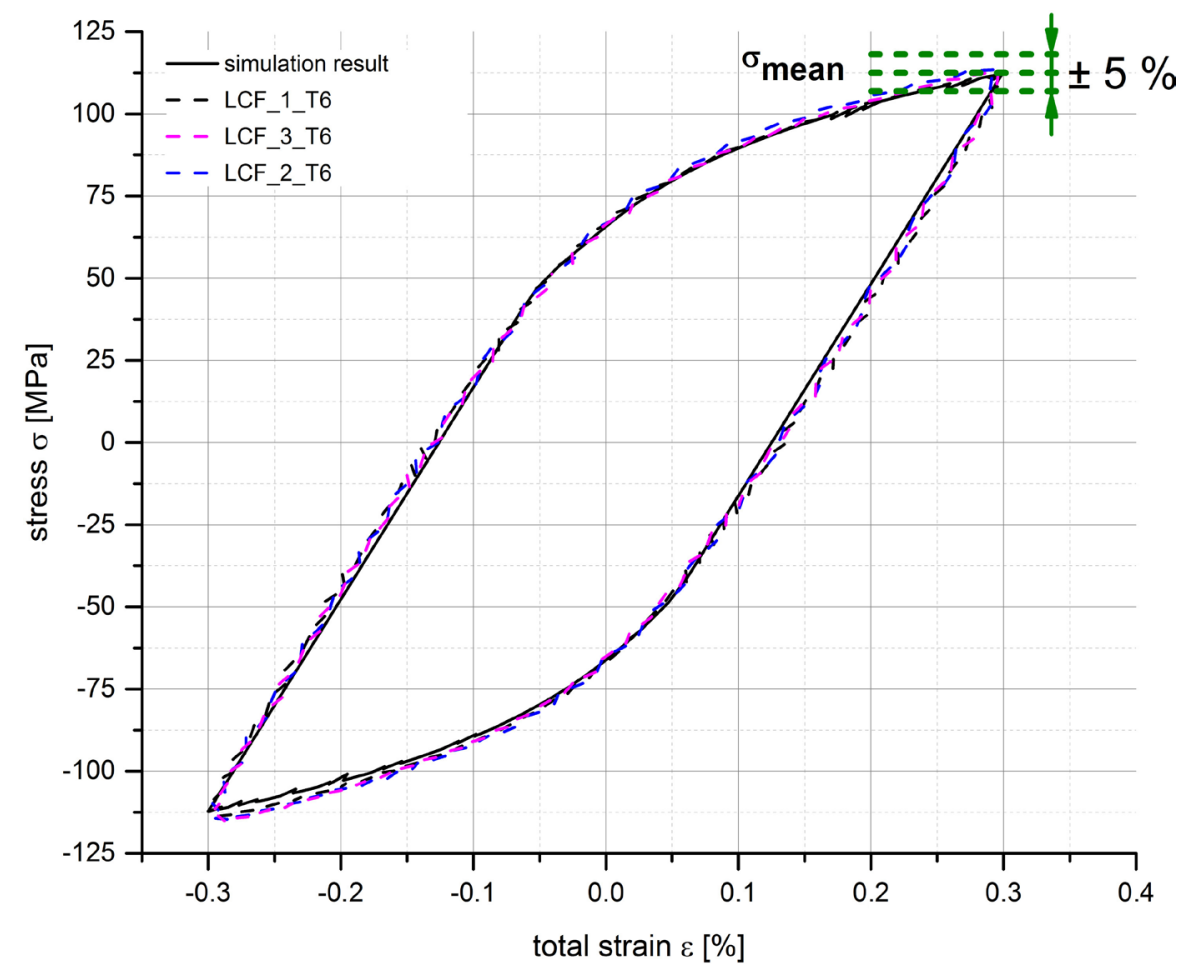

Figure 5. The figure shows test results based on the heat treated material of the $2000^{\text {th }}$ cycle and the simulation result of this cycle. 
Hysteresis from cycle 2

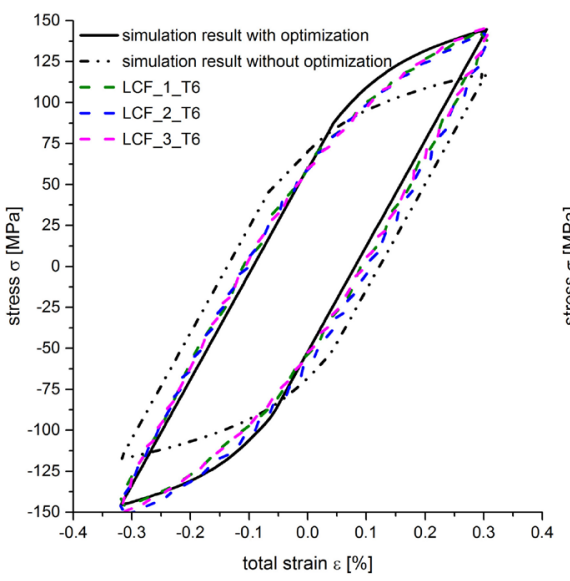

variation of the hysteresis from the first simulation and the simulation with optimized parameters is displayed in Figure 6 and in Table 2.

The second test range includes test results from as cast specimens. Thereby the tests were made by different strain amplitudes, as the test hysteresis in Figure 7 shows.

As input data for the isotropic fit all data up to the respective cycle $\mathrm{N}_{\mathrm{f}}$ were used to calculate the parameters. The kinematic parameters were determined by

Table 2. Test results from the heat treated specimens.

\begin{tabular}{|c|c|c|c|c|c|c|c|c|}
\hline \multirow{2}{*}{$\begin{array}{l}\text { cycle } \\
\text { number }\end{array}$} & LCF_1_T6 & LCF_2_T6 & LCF_3_T6 & \multirow{2}{*}{$\sigma_{\text {mean }}$} & \multirow{2}{*}{$\sigma_{\max }$} & \multirow{3}{*}{$\begin{array}{l}\text { dif. } \\
{[\%]}\end{array}$} & \multirow{3}{*}{$\begin{array}{c}\text { opt. } \\
\sigma_{\max } \\
{[\mathrm{MPa}]}\end{array}$} & \multirow{3}{*}{$\begin{array}{l}\text { dif. } \\
\text { [\%] }\end{array}$} \\
\hline & & $\sigma_{\text {testmax }}$ & & & & & & \\
\hline$[-]$ & \multicolumn{5}{|c|}{ [MPa] } & & & \\
\hline 2 & 143.1 & 142.4 & 145.2 & 143.5 & 118.0 & 17.8 & 144.7 & 0.84 \\
\hline 100 & 134.4 & 135.7 & 133.9 & 134.7 & 111.9 & 17.0 & 137.3 & 1.89 \\
\hline 500 & 123.7 & 126.2 & 124.3 & 124.7 & 112.1 & 10.1 & 120.3 & 3.70 \\
\hline 1000 & 117.8 & 120.0 & 118.9 & 118.9 & 112.1 & 6.1 & 113.6 & 4.46 \\
\hline 2000 & 111.4 & 113.4 & 112.7 & 112.5 & 112.2 & 0.3 & 112.2 & 0.30 \\
\hline
\end{tabular}

opt. $=$ optimized, dif. $=$ difference between $\sigma_{\text {mean }}$ and $\sigma_{\max }$
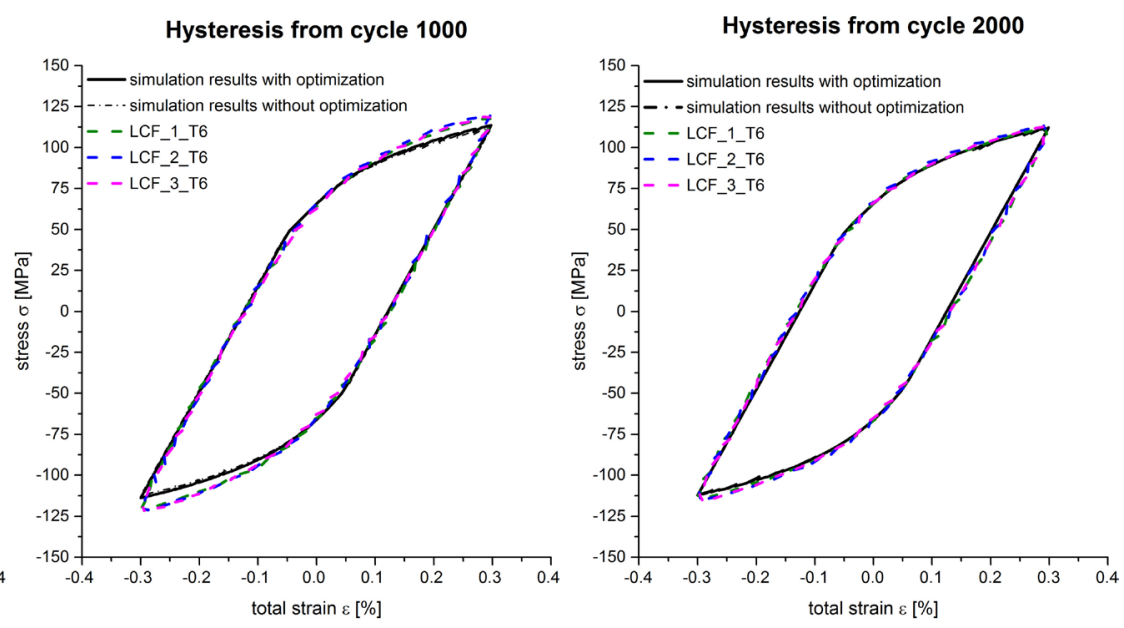

Figure 6. Comparison of the Simulation and test results of heat treatment material and different cycles.
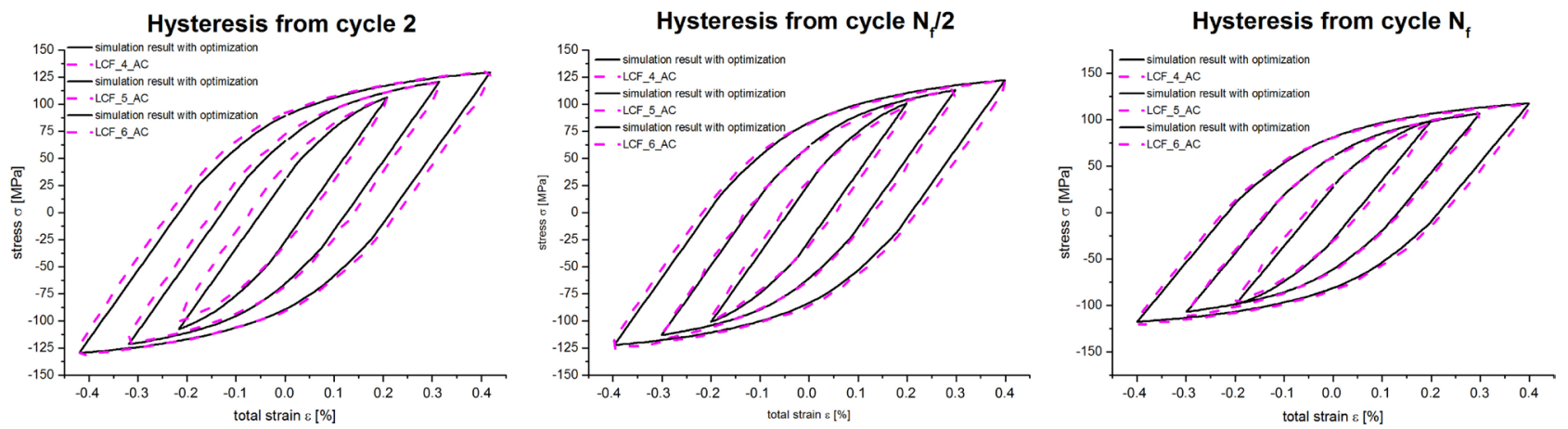

Figure 7. Comparison of the Simulation and test results by non heat treated material, different cycles and strain amplitudes. 
Table 3. Results of the non-heat treatment material.

\begin{tabular}{cccc}
\hline name & cycle number & test $\sigma_{\max }[\mathrm{MPa}]$ & simulation opt. $\sigma_{\max }[\mathrm{MPa}]$ \\
\hline LCF_4_AC & 2 & 105.7 & 106.3 \\
LCF_4_AC & $\mathrm{N}_{\mathrm{f}} / 2$ & 97.6 & 100.8 \\
LCF_4_AC & $\mathrm{N}_{\mathrm{f}}$ & 95.3 & 99.0 \\
LCF_5_AC & 2 & 120.1 & 120.9 \\
LCF_5_AC & $\mathrm{N}_{\mathrm{f}} / 2$ & 113.5 & 113.0 \\
LCF_5_AC & $\mathrm{N}_{\mathrm{f}}$ & 108.5 & 106.6 \\
LCF_6_AC & 2 & 129.9 & 129.4 \\
LCF_6_AC & $\mathrm{N}_{\mathrm{f}} / 2$ & 121.6 & 122.2 \\
LCF_6_AC & $\mathrm{N}_{\mathrm{f}}$ & 117.0 & 117.5 \\
\hline
\end{tabular}

the data set with the highest strain amplitude and cycle $\mathrm{N}_{\mathrm{f}}$. The described simulated hysteresis in Figure 7 are based on the optimized material parameter set. Table 3 shows that for each cycle and strain amplitude the $\sigma_{\max }$ from the simulated hysteresis are inside a range of $\pm 5 \%$ regarding to $\sigma_{\text {testmax }}$.

\section{Conclusions}

The test results of the T6 heat-treated material showed that the variation of $\sigma_{\max }$ is in a scatter of $\pm 5 \%$. Also the simulation result for the $2000^{\text {th }}$ cycle is inside this range. However, at the end of the CHP routine also the simulation results of the other chosen cycles are considering the default range of $\pm 5 \%$.

On the basis of the parameters, which were detected from the as cast specimens by strain amplitude of $\varepsilon_{\text {ampl }}=0.4 \%$, simulation by different strain amplitudes were carried out. The comparison of the different simulation results and the test data demonstrate that $\sigma_{\max }$ of the simulated hysteresis always lies in a scatter band of $\pm 5 \%$ regarding to $\sigma_{\text {mean }}$ of the tested hysteresis by the same cycles.

Overall, in relation to the CHP routine following conclusions can be made:

- The simulations describe the material behavior in a range which is sufficient. Thereby the critical point, during the estimation of the material parameters, is the determination of the boundary condition for fitting the young's modulus and the $\mathrm{R}$ values.

- The CHP routine determinate parameters that are able to simulate the stabilized cycle $\mathrm{N}_{\mathrm{f}} / 2$ or any cycle between one and $\mathrm{N}_{\mathrm{f}}$.

- The transportability of the estimated parameters is given, if the used finite-element-method includes the combined hardening law.

In the further research, the application of the highlighted routine should be widened so that visco-plastic material behavior could be considered.

\section{References}

[1] Dowling, N.E. (1999) Mechanical Behavior of Materials. Engineering Methods for Deformation, Fracture, and Fatigue. 2th Edition, Prentice Hall, Upper Saddle River. 
[2] Ramberg, W. and Osgood, W.R. (1943) Description of Stress-Strain Curves by Three Parameters. NASA Scientific and Technical Information Facility, Washington DC.

[3] Prager, W. (2006) The Theory of Plasticity. A Survey of Recent Achievements. Proceedings of the Institution of Mechanical Engineers, Rhode Island, 14 January 1955, 41-57.

[4] Ziegler, H. (1959) A Modification of Prager's Hardening Rule. Quarterly of Applied Mathematics, 17, 55-65. https://doi.org/10.1090/qam/104405

[5] Frederick, C.O. and Armstrong, P.J. (2007) A Mathematical Representation of the Multiaxial Bauschinger Effect. Materials at High Temperatures, 1, 1-26. https://doi.org/10.3184/096034007X207589

[6] Chaboche, J.L. (1986) Time-Independent Constitutive Theories for Cyclic Plasticity. International Journal of Plasticity, 2, 149-188. https://doi.org/10.1016/0749-6419(86)90010-0

[7] Kuhlmann-Wilsdorf, D. and Laird, C. (1979) Dislocation Behavior in Fatigue II. Friction Stress and Back Stress as Inferred from an Analysis of Hysteresis Loops. Materials Science and Engineering, 37, 111-120. https://doi.org/10.1016/0025-5416(79)90074-0

[8] Fournier, B., Sauzay, M., Caës, C., Noblecourt, M. and Mottot, M. (2006) Analysis of the Hysteresis Loops of a Martensitic Steel. Materials Science and Engineering. A, 437, 183-196. https://doi.org/10.1016/j.msea.2006.08.086

[9] Chaboche, J.L. (1989) Constitutive Equations for Cyclic Plasticity and Cyclic Viscoplasticity. International Journal of Plasticity, 5, 247-302. https://doi.org/10.1016/0749-6419(89)90015-6

[10] Halama, R. Sedlk, J. and Sofer, M. (2012) Phenomenological Modelling of Cyclic Plasticity. In: Peep, M., Ed., Numerical Modelling, Rijeka, 329-354. https://doi.org/10.5772/35902

[11] Ottosen, N.S. (1979) Nonlinear Kinematic Hardening under Non-Proportional Loading. Risø National Laboratory, Roskilde.

[12] Skelton, R.P., Maier, H.J. and Christ, H.-J. (1997) The Bauschinger Effect, Masing Model and the Ramberg-Osgood Relation for Cyclic Deformation in Metals. Materials Science and Engineering: A, 238, 377-390. https://doi.org/10.1016/S0921-5093(97)00465-6

[13] Borrego, L.P., Abreu, L.M., Costa, J.M. and Ferreira, J.M. (2004) Analysis of Low Cycle Fatigue in AlMgSi Aluminium Alloys. Engineering Failure Analysis, 11, 715-725. https://doi.org/10.1016/j.engfailanal.2003.09.003

[14] Strohhaussl, B., Stoschka, M., Winter, G. and Grün, F. (2017) Simulation of Lamellar Cast Iron Components under TMF-Loads. Materials Today: Proceedings, 4, 5957-5962. https://doi.org/10.1016/j.matpr.2017.06.077

[15] Lee, K. and Lee, S. (2016) A Comparison of Methods for Predicting the fatigue Life of Gray Cast Iron at Elevated Temperatures. Fatigue \& Fracture of Engineering Materials \& Structures, 39, 439-452. https://doi.org/10.1111/ffe.12368

[16] Zhou, D., Moosbrugger, J.C., Jia, Y. and Morrison, D.J. (2005) A Substructure Mixtures Model for the Cyclic Plasticity of Single Slip Oriented Nickel Single Crystal at Low Plastic Strain Amplitudes. International Journal of Plasticity, 21, 2344-2368. https://doi.org/10.1016/j.ijplas.2004.12.003 


\section{Nomenclature}

$\begin{array}{ll}\alpha & \text { back stress } \\ \varepsilon_{p} & \text { plastic strain } \\ \mathcal{E}_{\text {offset }} & \text { offset value to determinate the yield stress } \\ \sigma & \text { stress } \\ \sigma_{0} & \text { yield stress of each cycle } \\ \sigma_{\text {max }} & \text { maximal stress of a simulated hysteresis } \\ \sigma_{\text {mean }} & \text { arithmetic mean of the } \sigma \text { testmax values } \\ \sigma_{\text {offetmax }}, & \sigma_{\text {offsetmin parameters to determine the input data for fitting the young }} \quad \text { modulus } \\ \sigma_{\text {testmax }} & \text { maximal stress of a tested hysteresis } \\ \mathrm{C}, \gamma & \text { kinematic hardening parameters } \\ \mathrm{N}_{\mathrm{f}} & \text { last input cycle of estimation } \\ \mathrm{N}_{\text {kin }} & \text { cycle for fitting the kinematic hardening parameters } \\ \mathrm{p} & \text { accumulate plastic strain } \\ \mathrm{R} & \text { drag stress } \\ \mathrm{R}_{0} & \text { yield stress of the first cycle } \\ \mathrm{CHP} & \text { combined hardening parameter routine } \\ \mathrm{E} & \text { young modulus } \\ \mathrm{LCF} & \text { low cycle fatigue test } \\ \mathrm{Q}, \mathrm{b} & \text { isotropic hardening parameters }\end{array}$

